\title{
Two-dimensional Cellular Patterning on a Polymer Film Based on Interfacial Stiffness
}

Kento Kawabata, ${ }^{\ddagger}$ Masayasu Totani, ${ }^{*}$ Daisuke Kawaguchi, ${ }^{\ddagger \dagger}$ Hisao Matsuno ${ }^{*, \ldots \dagger}$ and Keiji

$$
\text { Tanaka*,+, }
$$

†Department of Applied Chemistry, Kyushu University, Fukuoka 819-0395, Japan

$\dagger^{\dagger}$ enter for Polymer Interface and Molecular Adhesion Science, Kyushu University, Fukuoka 819-0395, Japan

\footnotetext{
*To whom correspondence should be addressed

FAX: +81-92-802-2880 TEL: +81-92-802-2878

h-matsuno@cstf.kyushu-u.ac.jp (H.M.) \& k-tanaka@cstf.kyushu-u.ac.jp (K.T.)
} 


\section{POLYMER SYNTHESIS}

1.1. Materials. 2-hydroxyethyl methacrylate (HEMA, $>95.0 \%$ ), ethyl 2-bromoisobutyrate $(\mathrm{EBiB},>98.0 \%)$, lithium bromide ( $\mathrm{LiBr},>99.0 \%)$, and 2,2'-bipyridine (bpy, $>99.0 \%$ ) were purchased from Tokyo Chemical Industry (Tokyo, Japan). Copper(I) chloride $(\mathrm{CuCl}$, $>99.9 \%$ ) was purchased from Kishida Chemical (Osaka, Japan). Copper(II) chloride ( $\mathrm{CuCl}_{2}$, $>95.0 \%)$, methanol (>99.8\%), 2-butanone (>98.0\%), 1,4-dioxane (>99.5\%), N,Ndimethylformamide (DMF $>99.5 \%$ ), and deuterated methanol (methanol- $d_{4}, 99.8 \%$ atom D) were purchased from FUJIFILM Wako Pure Chemical (Osaka, Japan). All chemicals were used as received. Chromatorex BW-127ZH silica gel was purchased from Fuji Silysia Chemical (Kasugai, Aichi, Japan).

1.2. Characterizations. The chemical structure of a product was examined by ${ }^{1} \mathrm{H}$ nuclear magnetic resonance spectroscopy ( ${ }^{1} \mathrm{H}$ NMR, JNM-EC400, JEOL, Tokyo, Japan) using methanol- $d_{4}$ as a solvent at $298 \mathrm{~K}$. The number-average molecular weight $\left(M_{\mathrm{n}}\right)$ and polydispersity index $\left(M_{\mathrm{w}} / M_{\mathrm{n}}\right)$, where $M_{\mathrm{w}}$ is the weight-average molecular weight, of a polymer were examined by size exclusion chromatography system (SEC, HLC-8120GPC, TOSOH, Tokyo, Japan) equipped with columns packed with a micro-particulate gel of methacrylate polymer (TSKgel SuperAW5000 and AW4000, each: $6 \mathrm{~mm} \times 150 \mathrm{~mm}$ length, TOSOH) connected to a PU-980 pump (TOSOH) and an RI-930 refractive detector (TOSOH). DMF containing $10 \mathrm{mM}$ of $\mathrm{LiBr}$ was used as an eluant at $313 \mathrm{~K}$ at a flow rate of $1 \mathrm{~mL} \cdot \mathrm{min}^{-1}$. The glass transition temperature $\left(T_{\mathrm{g}}\right)$ was examined by differential scanning calorimetry (DSC, EXSTAR6000 DSC6220, Hitachi High-Tech Science, Tokyo, Japan). The sample was heated up to $423 \mathrm{~K}$ at a rate of $10 \mathrm{~K} \cdot \mathrm{min}^{-1}$ under a dry nitrogen purge and then cooled down to $298 \mathrm{~K}$ at the same rate. The third heating scan was used for the determination of $T_{\mathrm{g}}$. An empty alumina pan was used as a reference.

\subsection{Synthesis of Poly(2-hydroxyethyl methacrylate) (PHEMA). PHEMA was} synthesized by atom transfer radical polymerization (ATRP). ${ }^{\mathrm{S} 1, \mathrm{~S} 2}$ Scheme $\mathrm{S} 1$ shows the route for the synthesis of PHEMA.

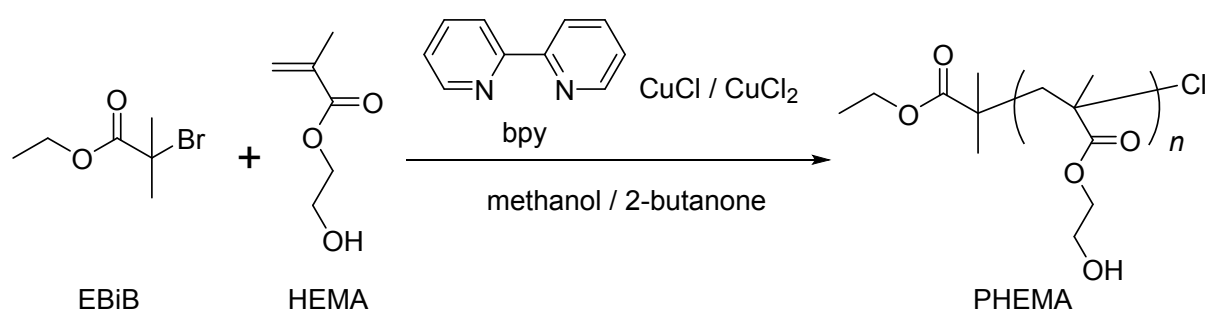

Scheme S1. Synthesis of PHEMA based on ATRP using an $\mathrm{EBiB}$ initiator with bpy/CuCl/CuCl 2 catalyst complex at $323 \mathrm{~K}$ in a mixed solvent of methanol/2-butanone with a ratio of $2: 3(\mathrm{v} / \mathrm{v})$; $[\mathrm{EBiB}] /[\mathrm{HEMA}] /[\mathrm{bpy}] /[\mathrm{CuCl}] /\left[\left[\mathrm{CuCl}_{2}\right]=7 / 3460 / 80 / 40 / 2 \mathrm{mM}\right.$. 
A typical procedure was as follows. A Schlenk tube equipped with a three-way stopcock was purged with argon (Ar) gas. $\mathrm{CuCl}(198 \mathrm{mg}, 2.00 \mathrm{mmol})$ and $\mathrm{CuCl}_{2}(13.5 \mathrm{mg}$, $0.100 \mathrm{mmol}$ ) were added to the Schlenk tube and then $27.0 \mathrm{~mL}$ of a mixed solvent composed of methanol/2-butanone with a ratio of 2:3 (v/v) and $21.0 \mathrm{~mL}$ of HEMA $(173 \mathrm{mmol})$ were added to the tube. The mixture was deoxygenated with Ar bubbling for $5 \mathrm{~min}$. Bpy $(625 \mathrm{mg}$, $4.00 \mathrm{mmol})$ was dissolved in $700 \mu \mathrm{L}$ of a $500 \mathrm{mM}$ of EBiB methanol solution $(0.350 \mathrm{mmol})$, and the mixture was then purged with Ar gas for $10 \mathrm{~min}$. Next, the mixture was injected into the Schlenk tube through the side-arm and kept at $323 \mathrm{~K}$ for $3.5 \mathrm{~h}$. The Schlenk tube was opened to air to quench the reaction. The reaction solution was diluted with methanol and passed through a silica gel column to remove the copper complex. The product was precipitated in 1,4-dioxane and dried under vacuum. A white powder was obtained; yield: $18.3 \mathrm{~g}(81.4 \%)$.

Panel (a) of Figure S1 shows the ${ }^{1} \mathrm{H}$ NMR spectrum for the product. Except for solvent peaks, all characteristic peaks were attributed to PHEMA; ${ }^{1} \mathrm{H}$ NMR (400 MHz, methanol- $d_{4}$, $\delta)$ : 4.14-3.93 ppm (2H, $\left.-\mathrm{CH}_{2}-\mathrm{O}\right), 3.85-3.67 \mathrm{ppm}\left(2 \mathrm{H},-\mathrm{CH}_{2}-\mathrm{OH}\right), 2.18-1.82 \mathrm{ppm}(2 \mathrm{H},-$ $\left.\mathrm{CH}_{2}-\right)$ 1.20-0.800 ppm (3H, $\left.-\mathrm{CH}_{3}\right)$. Panel (b) of Figure S1 shows an SEC curve for PHEMA calibrated with poly(methyl methacrylate) (PMMA) standards.

(a)

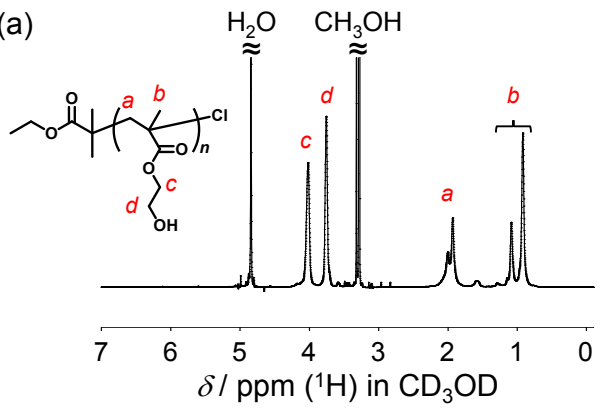

(b)

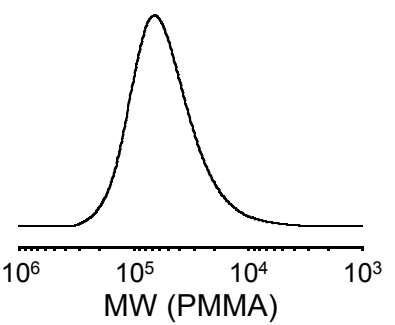

Figure S1. (a) ${ }^{1} \mathrm{H}$ NMR spectrum for a product acquired in methanol- $d_{4}$ at $298 \mathrm{~K}$. (b) SEC curve for the product. As an eluant, DMF containing $10 \mathrm{mM}$ of $\mathrm{LiBr}$ was used at a flow rate of $1.0 \mathrm{~mL} \cdot \mathrm{min}^{-1}$ at $313 \mathrm{~K}$, and PMMA standards were used for calibration.

\section{FILM PREPARATION}

2.1. Materials. LUDOX TM-50 colloidal silica ( $50 \mathrm{wt} \%$ dispersion in $\mathrm{H}_{2} \mathrm{O}$ ) was purchased from Merck (Darmstadt, Germany). Ethylene glycol (>99.0\%) and hydrogen peroxide $(>30.0 \%)$ were purchased from FUJIFILM Wako Pure Chemical. Sulfuric acid $(>95.0 \%)$ was purchased from KANTO CHEMICAL (Tokyo, Japan). Other reagents were the same as described above and all chemicals were used as received. Si wafers and borosilicate glasses were purchased from SUMCO (Tokyo, Japan) and Matsunami Glass Ind. (Osaka, Japan), 
respectively.

2.2. Characterizations. The particle size distribution of colloidal silica was examined by dynamic light scattering (DLS) using a Photal DLS-8000 (Otsuka Electronics, Osaka, Japan) equipped with an Ar laser $(488 \mathrm{~nm})$. The measurements at a scattering angle of $90^{\circ}$ were performed at $298 \mathrm{~K}$ in water. To avoid dust contamination, the dispersion liquid was filtered through a poly(tetrafluoroethylene) (PTFE)-made membrane with a mean pore diameter of $0.45 \mu \mathrm{m}$ (ADVANTEC Toyo Kaisha, Tokyo, Japan).

Figure S2 shows a DLS chart for colloidal silica. The hydrodynamic diameter was determined to be $22.4 \pm 4.8 \mathrm{~nm}$ and hereafter they are referred to as silica nano particles (SNPs).

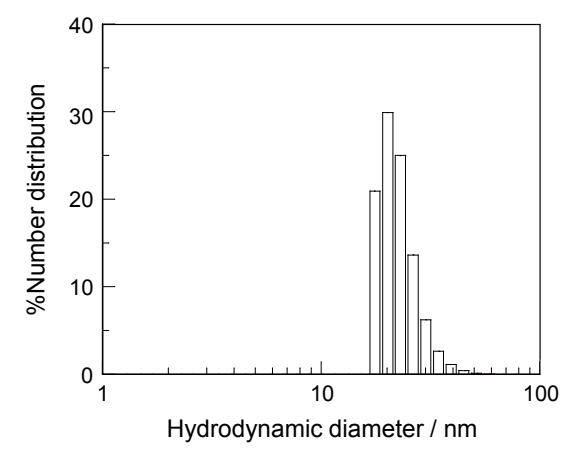

Figure S2. Size distribution of colloidal silica acquired in water.

2.3. Drawing an SNP Line Pattern. An aqueous SNP dispersion liquid was sonicated using a US-101 ultrasonic cleaner (SND, Suwa, Nagano, Japan) at $55 \mathrm{~W}$ for $30 \mathrm{~min}$ and then diluted by a factor of 10 with ethylene glycol. After filtrating the diluted SNP dispersion liquid using a PTFE-made membrane filter, it was loaded into an inkjet nozzle. Droplets of the SNP dispersion liquid were discharged at $500 \mathrm{~Hz}$ from the nozzle onto a solid substrate placed on an automatic stage on an automatic stage that was moving at $800 \mu \mathrm{m} \cdot \mathrm{s}^{-1}$. After leaving the SNP ink jetted substrate under an air atmosphere at room temperature for $1 \mathrm{~h}$ or more, it was then dried under vacuum at $473 \mathrm{~K}$ for $12 \mathrm{~h}$.

2.4. Spin-coating of PHEMA. PHEMA dissolved in a mixed solvent of ethanol and DMF with a ratio of 4:1 (v/v) was spin-coated on an SNP ink jetted substrate using a 1H-D7 spincoater (Mikasa, Tokyo, Japan). Just before spin-coating, the substrate was hydrophilized using a PDC-32G plasma cleaner (Harrick Scientific Products, New York, NY, US) at 100 Pa. The samples were then dried under vacuum at $380 \mathrm{~K}$, which was higher than the $T_{\mathrm{g}}$ of PHEMA by $20 \mathrm{~K}$ for $24 \mathrm{~h}$. 


\section{SURFACE AND INTERFACIAL CHARACTERIZATIONS}

3.1. X-ray Photoelectron Spectroscopy (XPS). Figure $\mathrm{S} 3$ shows an $\mathrm{Si}_{2 \mathrm{p} 3 / 2}$ XPS spectrum for an $\mathrm{Si}$ wafer with a pattern of SNP lines. The original spectrum for $\mathrm{Si}_{2 \mathrm{p}} \mathrm{T}_{12,3 / 2}$ acquired using a narrow beam size of X-ray was waveform-separated into the two contributions from $\mathrm{Si}_{2 \mathrm{p}} 1 / 2$ and $\mathrm{Si}_{2 \mathrm{p} 3 / 2}$, and then the former contribution was subtracted from the original spectrum. ${ }^{\mathrm{S} 3, \mathrm{~S} 4}$

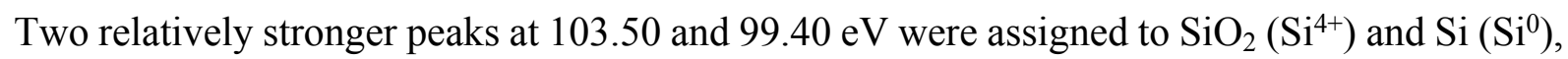
respectively. While $\mathrm{SiO}_{2}\left(\mathrm{Si}^{4+}\right)$ signals were derived from both the native oxide layer of the $\mathrm{Si}$ wafer and the SNP lines, $\mathrm{Si}\left(\mathrm{Si}^{0}\right)$ signals were only from the bulk region of the $\mathrm{Si}$ wafer. Other small peaks at $101.88,101.15$, and $100.35 \mathrm{eV}$ were attributed to $\mathrm{Si}_{2} \mathrm{O}_{3}\left(\mathrm{Si}^{3+}\right), \mathrm{SiO}\left(\mathrm{Si}^{2+}\right)$, and $\mathrm{Si}_{2} \mathrm{O}\left(\mathrm{Si}^{+}\right)$respectively, which existed in the native oxide layer of the $\mathrm{Si}$ wafer.

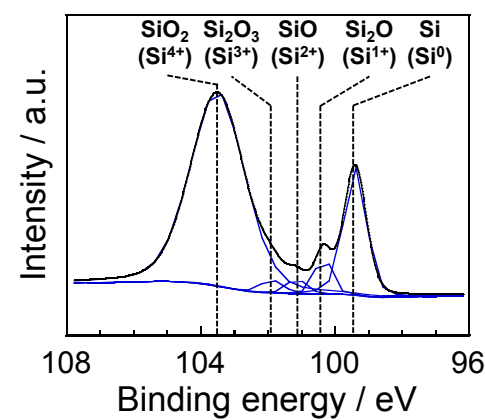

Figure S3. An $\mathrm{Si}_{2 \mathrm{p} 3 / 2}$ XPS spectrum for an SNP line-patterned $\mathrm{Si}$ wafer after spin-orbit splitting removal. Blue lines denote the fitting results.

Figure $\mathrm{S} 4$ shows a $\mathrm{C}_{1 \mathrm{~s}}$ core-level XPS spectrum for a PHEMA film on an SNP line-patterned Si wafer. Three peaks observed at 289.2, 286.5, and $285.0 \mathrm{eV}$ were attributed to carbonyl $\left(\mathrm{C}^{*}=\mathrm{O}\right)$, ether $\left(\mathrm{C}^{*}-\mathrm{O}\right)$, and neutral $\left(\mathrm{C}-\mathrm{C}^{*}-\mathrm{C}\right)$ carbons, respectively. ${ }^{\mathrm{S} 5}$ The intensity ratio of these peaks was 1:2:3, which corresponded to the ideal ratio based on the chemical structure of PHEMA.

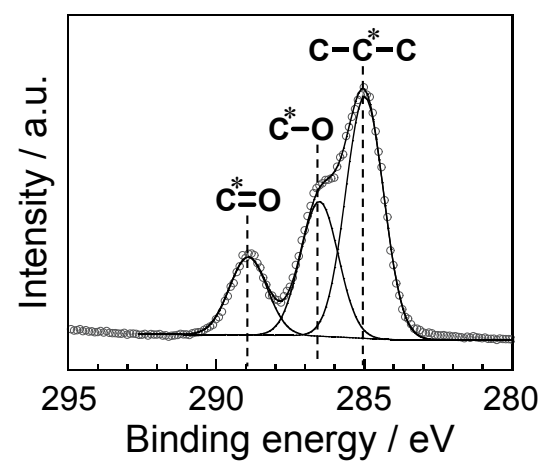

Figure S4. A $\mathrm{C}_{1 \mathrm{~s}}$ core-level XPS spectrum for a PHEMA film on an SNP line-patterned Si wafer. Open symbols denote experimental data and curves show the fitting results. 
Figure $\mathrm{S} 5$ shows the intensity of $\mathrm{C}_{1 \mathrm{~s}}, \mathrm{O}_{1 \mathrm{~s}}$, and $\mathrm{Si}_{2 \mathrm{p} 3 / 2}$ peaks $\left(I_{\mathrm{C} 1 \mathrm{~s}}, I_{\mathrm{O} 1 \mathrm{~s}}\right.$, and $\left.I_{\mathrm{Si2p} 3 / 2}\right)$ for the PHEMA film on the SNP line-patterned Si wafer as a function of sputtering time. The intensity of $\mathrm{SiO}_{2}\left(\mathrm{Si}^{4+}\right)\left(I_{\mathrm{Si} 2 \mathrm{p} 3 / 2 \mathrm{SiO} 2}\right)$ obtained by the wave separation is also shown. The $I_{\mathrm{C} 1 \mathrm{~s}}$ was higher than others at the beginning then decreased with increasing time. This reflects the fact that the PHEMA film was well sputtered. The $I_{\mathrm{O} \text { s }}$ initially increased, and started to decrease at around $17 \mathrm{~min}$. Although the removal of the PHEMA component contributed to the reduction of oxygen atoms, the increase in $\mathrm{O}_{1 \mathrm{~s}}$ signals mainly represented the appearance of SNPs and the native oxide layer of the $\mathrm{Si}$ wafer. Also, the successive decrease in $\mathrm{O}_{1 \mathrm{~s}}$ signals corresponded to their removal of them. The $I_{\mathrm{Si} 2 \mathrm{p} 3 / 2 \mathrm{SiO} 2}$ was below the detection limit for the first $8 \mathrm{~min}$, then increased and subsequently decreased. This behavior also represents the appearance and disappearance of SNPs as well as the native oxide layer. On the other hand, the $I_{\mathrm{Si2p} 3 / 2}$ started to increase at around $8 \mathrm{~min}$ due to the appearance of SNPs and the Si wafer substrate, and kept gradually increasing even after the longer sputtering time of $30 \mathrm{~min}$, meaning that eventually only the bulk component of the Si wafer remained.

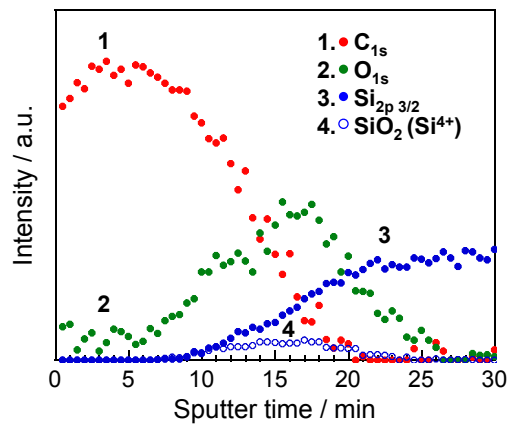

Figure S5. Signal intensity of $\mathrm{C}_{1 \mathrm{~s}}, \mathrm{O}_{1 \mathrm{~s}}$, and $\mathrm{Si}_{2 \mathrm{p} 3 / 2}$ peaks $\left(I_{\mathrm{Cl} 1 \mathrm{~s}}, I_{\mathrm{O} 1 \mathrm{~s}}\right.$, and $\left.I_{\mathrm{Si} 2 \mathrm{p} 3 / 2}\right)$ for a PHEMA film on an SNP line-patterned Si wafer as a function of sputtering time. The signal intensity of an $\mathrm{SiO}_{2}$ component $\left(I_{\mathrm{Si2p} 3 / 2 \mathrm{SiO} 2}\right)$ obtained by the wave separation is also shown. The period of the $\mathrm{Ar}$ sputtering was $30 \mathrm{~s}$, and the spectra were acquired after every sputtering. The number of sputtering was 60 , yielding a total sputtering time of $30 \mathrm{~min}$.

3.2. Atomic Force Microscopy (AFM). Panel (a) of Figure S6 shows an AFM height image for the PHEMA film on the SNP line-patterned Si wafer acquired in water at room temperature. To quantify the film thickness, the film was partially cut by a blade. Panel (b) of Figure $\mathrm{S} 6$ shows a cross-sectional view along the white line $A B$ in (a). The difference in height, that is, the thickness of the PHEMA film was estimated to be approximately $140 \mathrm{~nm}$. 
(a)

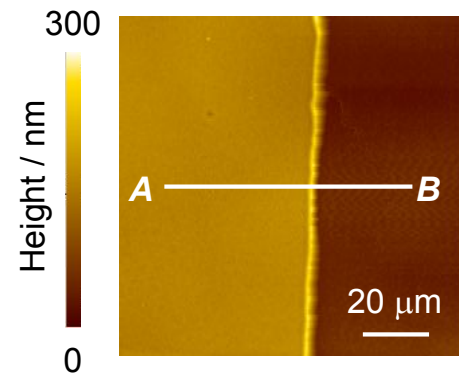

(b)

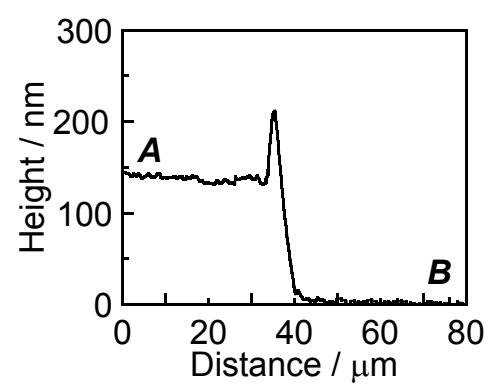

Figure S6. (a) AFM height image for a PHEMA film on an SNP line-patterned Si wafer acquired in water. The film was partially cut by a blade. (b) A cross-sectional view along the white line $A B$ in (a).

\section{CELL CULTURE}

Figure S7 shows phase-contrast microscopic images for NIH/3T3 cells cultured on a tissue culture polystyrene (TCPS) well as a reference. The culturing times were (a) 3, (b) 6, and (c) $18 \mathrm{~h}$, respectively. NIH/3T3 cells firmly adhered even after $3 \mathrm{~h}$, and subsequently, normal cell spreading was observed, as shown in $(b, c)$.
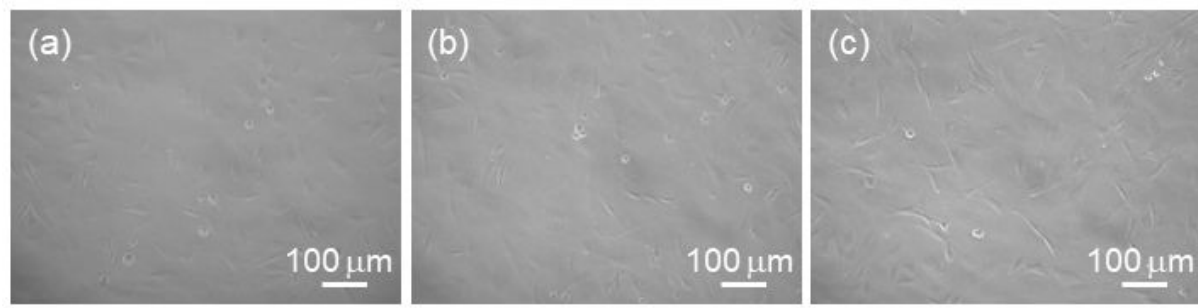

Figure S7. (a-c) Phase-contrast microscopic images for NIH/3T3 fibroblasts adhered on a TCPS well observed after (a) 3-, (b) 6-, and (c) 18 h-culture, respectively.

Figure S8 shows a phase-contrast microscopic image for NIH/3T3 cells adhered on the PHEMA film prepared on the SNP-patterned substrate observed after $18 \mathrm{~h}$-culture. The image was acquired after the substitution of culture medium with phosphate buffered saline (PBS).

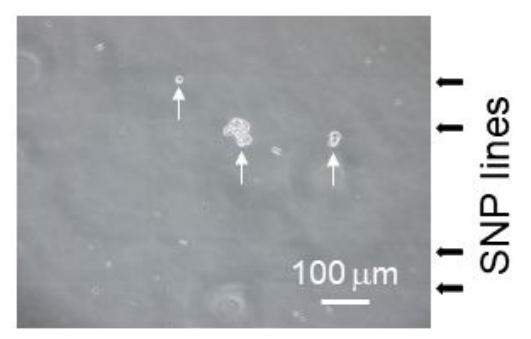

Figure S8. Phase-contrast microscopic image for NIH/3T3 fibroblasts adhered on the PHEMA film prepared on the SNP-patterned substrate after $18 \mathrm{~h}$-culture. The image was acquired after the substitution of culture medium with PBS. 
Figure S9 shows phase-contrast microscopic images for NIH/3T3 cells adhered on the PHEMA film with various thicknesses prepared on flat borosilicate glasses.
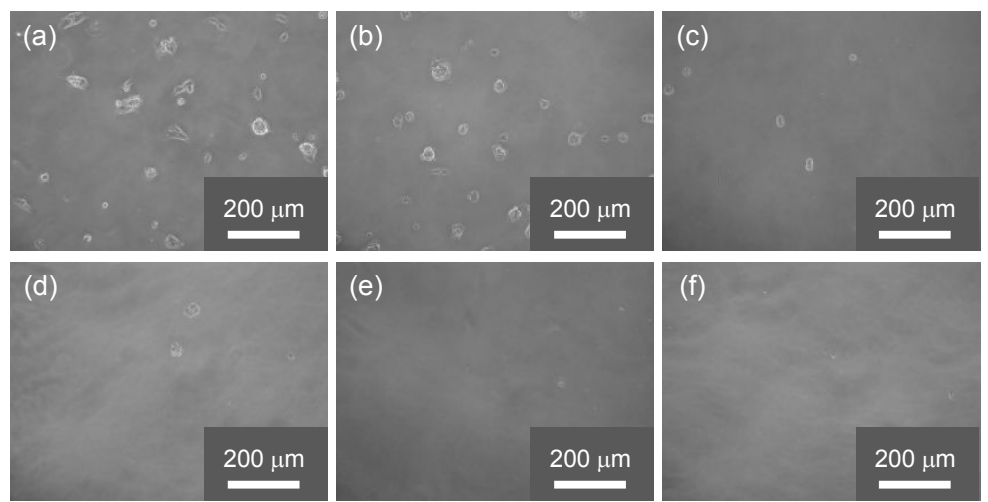

Figure S9. Phase-contrast microscopic images for NIH/3T3 fibroblasts cultured on PHEMA films with different thicknesses prepared on flat borosilicate glass substrates. Culture was performed in DMEM at $310 \mathrm{~K}$ for $24 \mathrm{~h}$. The thicknesses of PHEMA were approximately (a) 30, (b) 50, (c) 80 , (d) 130 , (e) 200 , and (f) $250 \mathrm{~nm}$, respectively.

\section{REFERENCES}

(S1) Robinson, K. L.; Khan, M. A.; de Paz Banes, M.V.; Wang, X. S.; Armes, S. P. Controlled Polymerization of 2-Hydroxyethyl Methacrylate by ATRP at Ambient Temperature. Macromolecules 2001, 34, 3155-3158.

(S2) Weaver, J. V. M.; Bannister, I.; Robinson, K. L.; Bories-Azeau, X.; Armes, S. P. Stimulus-Responsive Water-Soluble Polymers Based on 2-Hydroxyethyl Methacrylate. Macromolecules 2004, 37, 2395-2403.

(S3) Seah, M. P.; Spencer, S. J. Ultrathin $\mathrm{SiO}_{2}$ on Si. II. Issues in Quantification of the Oxide Thickness. Surf. Interface Anal. 2002, 33, 640-652.

(S4) Seah, M. P.; Spencer, S. J.; Bensebaa, F.; Vickridge, I.; Danzebrink, H.; Krumrey, M.: Gross, T.; Oesterle, W.; Wendler, E.; Rheinländer, B.; Azuma, Y.; Kojima, I.; Suzuki, N.; Suzuki, M.; Tanuma, S.; Moon, D. W.; Lee, H. J.; Cho, H. M.; Chen, H. Y.; Wee, A. T. S.; Osipowicz, T.; Pan, J. S.; Jordaan, W. A.; Hauert, R.; Klotz, U.; van der Marel, C.; Verheijen, M.; Tamminga, Y.; Jeynes, C.; Bailey, P.; Biswas, S.; Falke, U.; Nguyen, N. V.; Chandler-Horowitz, D.; Ehrstein, J. R.; Muller, D.; Dura, J. A. Critical Review of the Current Status of Thickness Measurements for Ultrathin $\mathrm{SiO}_{2}$ on Si Part V: Results of a CCQM Pilot Study. Surf. Interface Anal. 2004, 36, 1269-1303.

(S5) Castner, G. D.; Ratner, D. B.; Hirano, A.; Nakahama, S.; Characterization of Poly(2Hydroxyethyl Methacrylate) (PHEMA) by XPS. Surf. Sci. Spectra 1996, 4, 14-20. 